\title{
Milk metabolome relates enteric methane emission to milk synthesis and energy metabolism pathways
}

\author{
E. C. Antunes-Fernandes, ${ }^{*} \dagger$ S. van Gastelen, ${ }^{\star} \ddagger$ J. Dijkstra, $\ddagger$ K. A. Hettinga,,${ }^{1}$ and J. Vervoort§ \\ ${ }^{*}$ Top Institute Food and Nutrition, PO Box 557, 6700 AN Wageningen, the Netherlands \\ †Food Quality and Design Group, Wageningen University, PO Box 17, $6700 \mathrm{AH}$ Wageningen, the Netherlands \\ $\ddagger$ Animal Nutrition Group, Wageningen University, PO Box 338, 6700 AH Wageningen, the Netherlands \\ §Laboratory of Biochemistry, Wageningen University, Dreijenlaan 3, 6703 HA, Wageningen, the Netherlands
}

\begin{abstract}
Methane $\left(\mathrm{CH}_{4}\right)$ emission of dairy cows contributes significantly to the carbon footprint of the dairy chain; therefore, a better understanding of $\mathrm{CH}_{4}$ formation is urgently needed. The present study explored the milk metabolome by gas chromatography-mass spectrometry (milk volatile metabolites) and nuclear magnetic resonance (milk nonvolatile metabolites) to better understand the biological pathways involved in $\mathrm{CH}_{4}$ emission in dairy cattle. Data were used from a randomized block design experiment with 32 multiparous Holstein-Friesian cows and 4 diets. All diets had a roughage:concentrate ratio of 80:20 (dry matter basis) and the roughage was grass silage (GS), corn silage (CS), or a mixture of both (67\% GS, $33 \%$ CS; $33 \%$ GS, $67 \%$ CS). Methane emission was measured in climate respiration chambers and expressed as $\mathrm{CH}_{4}$ yield (per unit of dry matter intake) and $\mathrm{CH}_{4}$ intensity (per unit of fat- and protein-corrected milk; FPCM). No volatile or nonvolatile metabolite was positively related to $\mathrm{CH}_{4}$ yield, and acetone (measured as a volatile and as a nonvolatile metabolite) was negatively related to $\mathrm{CH}_{4}$ yield. The volatile metabolites 1-heptanol-decanol, 3-nonanone, ethanol, and tetrahydrofuran were positively related to $\mathrm{CH}_{4}$ intensity. None of the volatile metabolites was negatively related to $\mathrm{CH}_{4}$ intensity. The nonvolatile metabolites acetoacetate, creatinine, ethanol, formate, methylmalonate, and $\mathrm{N}$-acetylsugar A were positively related to $\mathrm{CH}_{4}$ intensity, and uridine diphosphate (UDP)-hexose $\mathrm{B}$ and citrate were negatively related to $\mathrm{CH}_{4}$ intensity. Several volatile and nonvolatile metabolites that were correlated with $\mathrm{CH}_{4}$ intensity also were correlated with FPCM and not significantly related to $\mathrm{CH}_{4}$ intensity anymore when FPCM was included as covariate. This suggests that changes in these milk metabolites may be related to
\end{abstract}

Received August 12, 2015.

Accepted April 15, 2016

${ }^{1}$ Corresponding author: kasper.hettinga@wur.nl changes in milk yield or metabolic processes involved in milk synthesis. The UDP-hexose B was correlated with FPCM, whereas citrate was not. Both metabolites were still related to $\mathrm{CH}_{4}$ intensity when FPCM was included as covariate. The UDP-hexose $\mathrm{B}$ is an intermediate of lactose metabolism, and citrate is an important intermediate of Krebs cycle-related energy processes. Therefore, the negative correlation of UDP-hexose B and citrate with $\mathrm{CH}_{4}$ intensity may reflect a decrease in metabolic activity in the mammary gland. Our results suggest that an integrative approach including milk yield and composition, and dietary and animal traits will help to explain the biological metabolism of dairy cows in relation to methane $\mathrm{CH}_{4}$ emission.

Key words: dairy cow, milk metabolome, enteric methane emission, energy metabolism

\section{INTRODUCTION}

Enteric methane $\left(\mathrm{CH}_{4}\right)$ production in ruminants mainly occurs in the rumen and is a natural byproduct of microbial feed fermentation and degradation, an essential process to provide nutrients to the animal. An increase of DMI results in a higher $\mathrm{CH}_{4}$ production because more substrate is available for rumen microbiota to degrade, but diet characteristics, including the type of carbohydrates and fat content, can also have a large effect on $\mathrm{CH}_{4}$ production (Kirchgebner et al., 1995). Due to the large contribution (approximately 52\%) of $\mathrm{CH}_{4}$ emission to the total greenhouse gas (GHG) emissions of the dairy sector (Gerber et al., 2013), mitigation strategies have been widely investigated (Hristov et al., 2013). Dietary changes to influence $\mathrm{CH}_{4}$ emission are among the most direct $\mathrm{CH}_{4}$ mitigation strategies (Knapp et al., 2014). Their importance increases because they are also candidates for implementation at dairy farms. According to Dijkstra et al. (2011), evaluating dietary mitigation strategies should be based on $\mathrm{CH}_{4}$ production relative to feed intake because it avoids confounding effects of DMI on total $\mathrm{CH}_{4}$ production $\left(\mathrm{CH}_{4}\right.$ produced per animal). However, uncertainties in measuring DMI at farm level makes an accurate rela- 
tion of $\mathrm{CH}_{4}$ to DMI difficult in practice (Bannink et al., 2011). Others have related $\mathrm{CH}_{4}$ mitigation strategies to their effect on the product (milk) of a dairy farm (Knapp et al., 2014).

To assess GHG emissions by the dairy chain, it is also possible to relate $\mathrm{CH}_{4}$ production per unit of milk [usually expressed per unit of ECM or per unit of fatand protein-corrected milk (FPCM)]. Higher production levels related to nutritional and nonnutritional management strategies may reduce $\mathrm{CH}_{4}$ emissions per unit of milk (FAO, 2010). Emissions per unit of animal product reflect the accuracy of management practices on the composite of feed intake, GHG emission, and animal productivity (FAO, 2010). Therefore, evaluating $\mathrm{CH}_{4}$ production in relation to feed intake and in relation to milk production are complementary.

Many studies have focused on the effect of $\mathrm{CH}_{4}$ mitigation strategies on milk composition, but mainly on the macro constituents level (Mohammed et al., 2011; Hart et al., 2015). Less attention has been paid to individual metabolites of milk, with the exception of milk fatty acids (MFA; Odongo et al., 2007; Chilliard et al., 2009). This focus on MFA is because of the relation between MFA and ruminal activity with respect to microbial metabolism and type of VFA formed (Vlaeminck and Fievez, 2005). Changes in feeding can result in clear changes in MFA, which are partly related to how feed is degraded in the rumen (Halmemies-Beauchet-Filleau et al., 2014). Although MFA may predict $\mathrm{CH}_{4}$ emission accurately within a limited range of dietary variation (e.g., variation in lipid source only; Chilliard et al., 2009), MFA cannot accurately predict the differences in $\mathrm{CH}_{4}$ emission on a wider range of diets (van Lingen et al., 2014; Williams et al., 2014).

Milk volatile metabolite and nonvolatile metabolite profiles can be used to monitor animal health, feeding regimens, and metabolism in dairy cows. Based on different feeding regimens, indole and skatole present in the volatile fraction of milk were pointed out as indicative of the feeding regimen of dairy cows (Toso et al., 2002; Croissant et al., 2007). Further, Hettinga et al. (2008) used the milk volatile metabolite profile to detect and differentiate mastitis caused by different pathogens. Also, Klein et al. (2012) indicated the ratio of the nonvolatiles glycerophosphocholine and choline as possible predictor for developing ketosis in dairy cows and Lu et al. (2013), showed that phosphate sugars can be related to energy balance of the cow, due to a different organization of the epithelial membrane in relation to energy balance. These authors also showed that determining milk components using different techniques simultaneously can be useful for a more integrated understanding of the metabolism of cows (Klein et al., 2010; Lu et al., 2013).
Many fields of research analyze the same bio-matrix with different methods and integrate the resulting information to better monitor, predict, and interpret biological processes. Although milk volatile metabolite and nonvolatile metabolite profiles have been used to monitor digestion and metabolism in dairy cows, to the best of our knowledge these profiles have not been related to $\mathrm{CH}_{4}$ emission. The present study explores the milk metabolome by GC-MS (GC-MS metabolomics; milk volatile metabolites) and proton nuclear magnetic resonance $\left({ }^{1} \mathbf{H}-\mathbf{N M R}\right.$ metabolomics; milk nonvolatile metabolites) to better understand the biological pathways involved in $\mathrm{CH}_{4}$ emission.

\section{MATERIALS AND METHODS}

\section{Experimental Design}

Data from a completely randomized block design experiment were used with a total of 32 multiparous lactating Holstein-Friesian cows fed 4 diets that differed in grass silage (GS) and corn silage (CS) content. The experiment was fully described by van Gastelen et al. (2015). The experiment was conducted in 2012 in accordance with Dutch law and approved by the Animal Care and Use Committee of Wageningen University (Wageningen, the Netherlands).

The 4 diets had a roughage:concentrate ratio of 80:20 based on DM content. The composition of the concentrate was similar for all diets, whereas the roughage consisted of $100 \%$ GS, $67 \%$ GS and $33 \%$ CS, $33 \%$ GS and $67 \% \mathrm{CS}$, and $100 \% \mathrm{CS}$ (ingredient as percentage of the total amount of roughage in the diet, all DM basis). Feed intake was restricted (95\% of ad libitum DMI) to avoid confounding effects of DMI on $\mathrm{CH}_{4}$ production. After an adaptation period of $12 \mathrm{~d}$, on d 13, cows were housed in climate respiration chambers (CRC) for a 5 -d period. Cows were milked and fed twice daily. Production of $\mathrm{CH}_{4}$ was determined in 10 min intervals during 3 full 24 -h periods in the CRC. The details of the CRC used in this experiment are extensively described by van Gastelen et al. (2015).

\section{Milk Yield and Composition}

Milk yield was recorded during each milking, and a milk sample $(10 \mathrm{~mL})$ was collected for analyses of fat, protein, and lactose content by mid-infrared spectroscopy by Qlip (Zutphen, the Netherlands). In addition, a representative milk sample $(5 \mathrm{~g} / \mathrm{kg}$ of milk production) was obtained at each milking from each cow. The first milk sample was collected on d 13 in the afternoon and the last milk sample was collected on $\mathrm{d}$ 17 in the morning, whereas cows were housed in the 
CRC. Sodium azide $(0.05 \% \mathrm{wt} / \mathrm{wt})$ was added to the pooled samples of the first 4 milkings, followed by the same procedure for milking 5 to 8 in a separate bottle. Both bottles were stored at $5^{\circ} \mathrm{C}$. After the last milking, these 2 sub-samples (milkings 1 to 4 and 5 to 8 ) were pooled, and stored in $10-\mathrm{mL}$ aliquots at $-40^{\circ} \mathrm{C}$ for milk composition analyses.

\section{Analytical Procedures}

Volatile Metabolites. To determine the volatile metabolite profile, GC-MS metabolomics was performed based on the method described by Hettinga et al. (2008) and Settachaimongkon et al. (2014). Milk samples were thawed overnight in a refrigerator $\left(7^{\circ} \mathrm{C}\right)$. A 5 -mL milk sample was preheated in $10-\mathrm{mL}$ vials sealed with silicon/Teflon septa and magnetic caps for $1 \mathrm{~min}$ at $60^{\circ} \mathrm{C}$. Volatile metabolites were extracted from the headspace for 5 min with a $75-\mu \mathrm{m}$ PDMScarboxen SPME fiber (Supelco, Bellefonte, PA) using the Triplus autosampler (CTC Analytics Ag, Zwingen, Switzerland). The volatile metabolites were thermally desorbed from the fiber by heating it in a Best PTV injector (Thermo-Finnigan, San Jose, CA) with an empty liner for $5 \mathrm{~min}$ at $250^{\circ} \mathrm{C}$. The fiber was subsequently cleaned for $10 \mathrm{~min}$ at $290^{\circ} \mathrm{C}$. Vials without milk (only air) were used as blank samples.

Gas chromatography separation of volatile metabolites was performed on a Trace GC/MS (Thermo-Fisher Scientific, Waltham, MA). Volatiles were separated on a polar Stabilwax column of $30 \mathrm{~m}$ length, $0.32 \mathrm{~mm}$, and $1-\mu \mathrm{m}$ film thickness (Restek, Breda, the Netherlands). Oven temperature was kept at $40^{\circ} \mathrm{C}$ for $3 \mathrm{~min}$, after which it was increased to $220^{\circ} \mathrm{C}$ at $15^{\circ} \mathrm{C} / \mathrm{min}$, with 1 min holding at $220^{\circ} \mathrm{C}$. Helium at a flow rate of 1.5 $\mathrm{mL} / \mathrm{min}$ was used as a carrier gas. Mass spectrometry analysis was performed in electron impact mode $(70$ $\mathrm{eV}$ ) in the range of 33 to $250 \mathrm{~m} / z$, with 2 scans/s; the mass range of $m / z 33$ to 250 was used. The ion source was kept at $225^{\circ} \mathrm{C}$.

The resulting chromatograms were analyzed using the AMDIS software (NIST, Gaithersburg, MD); data were deconvoluted to obtain pure mass spectra for improved peak identification. Identification of volatile metabolites was based on AMDIS software referred to NIST/EPA/NIH database (http://www.nist.gov/srd/ nist1a.cfm) and matching mass spectra and retention time with an in-house library based on previous milk analyses (Hettinga et al., 2009). Fragment patterns were not specific enough to identify the chain length of 3 alkanes and these were labeled as alkane A, B, and C. Peak integration was subsequently performed using the XCalibur software package (Thermo-Scientific, Austin, TX). Peak area of the milk samples was corrected for the peak area of the blank samples, resulting in a peak area in arbitrary units that was used for statistical analyses.

Nonvolatile Metabolites. To determine the nonvolatile metabolite profile of the milk samples, ${ }^{1} \mathrm{H}$ NMR metabolomics was performed. The procedure is described in detail by Lu et al. (2013). In short, milk samples were ultra-centrifuged to isolate milk serum. One-dimensional nuclear Overhauser enhancement spectroscopy (1-D-NOESY) spectra were obtained for all milk serum samples, using a nuclear magnetic resonance Bruker spectrometer Avance III with a 600 $\mathrm{MHz} / 54 \mathrm{~mm}$ UltraShielded Plus magnet equipped with a CryoPlatform cryogenic cooling system, a BCU-05 cooling unit, an ATM automatic tuning and matching unit (Bruker, Rheinstetten, Germany). To assign milk serum nonoverlapping metabolite resonances, comparisons were made with published literature (Klein et al., 2010, 2012), the Human Metabolome Database version 2.0 online library (http://www.hmdb.ca), as well as internal standards. The peak area of each assignment is relative to the calibration standard 3-trimethylsilyl2,2,3,3-tetradeuteropropionate, resulting in a relative peak area in arbitrary units that was used for statistical analyses.

\section{Statistical Analysis}

One cow was excluded from the experiment, because of large feed residuals while housed in the CRC, which resulted in much lower DMI compared with the last $4 \mathrm{~d}$ in the tie-stall and the other cows in that block (van Gastelen et al., 2015). In addition, the results of GC-MS metabolomics of another cow could not be used because these results were considered outliers (i.e., 9 from 25 volatile metabolites were not found in the milk of this cow, and acetone was 10 times more present in the milk of this cow compared with the milk of other cows). Last, the results of ${ }^{1} \mathrm{H}-\mathrm{NMR}$ metabolomics of a third cow could not be used because the sample showed repeatedly a high background interference, which impaired peak integration. Therefore, relations between metabolites measured with both techniques were based on 29 samples, whereas all remaining data analyses of volatile and nonvolatile metabolites, $\mathrm{CH}_{4}$ emission, and production traits were based on 30 samples.

Data on DMI, milk production, milk composition, and MFA are described by van Gastelen et al. (2015). The summary statistics of the volatile metabolites and nonvolatile metabolites are presented in Supplemental Tables S1 and S2, respectively (http://dx.doi. org/10.3168/jds.2015-10248). All statistical analyses were done using SPSS version 21 (SPSS Inc., Chicago, IL). 
The relations between individual volatile metabolites or nonvolatile metabolites, and $\mathrm{CH}_{4}$ intensity $(\mathrm{g} / \mathrm{kg}$ of FPCM) or $\mathrm{CH}_{4}$ yield $(\mathrm{g} / \mathrm{kg}$ of DMI) were established by linear regression with $\mathrm{CH}_{4}$ intensity and $\mathrm{CH}_{4}$ yield as dependent variables and milk volatile or nonvolatile metabolites as independent variables. All coefficients were calculated over all diets. To evaluate the influence of FPCM on the established relations between individual volatile metabolites or nonvolatile metabolites and $\mathrm{CH}_{4}$ intensity, FPCM was included as a covariate in the linear regressions. To evaluate the influence of diet on the established relations between individual volatile metabolites or nonvolatile metabolites, and $\mathrm{CH}_{4}$ yield and intensity, dietary treatment was included as a covariate in the linear regressions. Pearson correlation coefficients between milk (non)volatile metabolites and milk and animal traits were determined, with a 2 -tailed test for significance $(P<0.05)$. Multivariate analysis of the data was done by principal component analysis in $\mathrm{R}$ version 3.2.3. ( $\mathrm{R}$ Core Team, 2013).

\section{RESULTS AND DISCUSSION}

\section{Relation Between Individual Metabolites and $\mathrm{CH}_{4}$ Intensity or Yield}

Volatile Metabolites. In the present study, a total of 25 volatile metabolites were identified. These included ketones, aldehydes, alcohols, hydrocarbons, sulfur compounds, esters, and terpenes. The relations between each volatile metabolite and $\mathrm{CH}_{4}$ intensity $(\mathrm{g} /$ $\mathrm{kg}$ of $\mathrm{FPCM})$ and $\mathrm{CH}_{4}$ yield $(\mathrm{g} / \mathrm{kg}$ of DMI) are shown in Tables 1 and 2, respectively.

The volatile metabolites 1-heptanol-decanol, 3-nonanone, ethanol, and tetrahydrofuran were positively related $(P<0.044)$ to $\mathrm{CH}_{4}$ intensity, and none of the volatile metabolites were negatively related to $\mathrm{CH}_{4}$ intensity. None of the volatile metabolites were positively related to $\mathrm{CH}_{4}$ yield, whereas acetone was negatively related $(P=0.043)$ to $\mathrm{CH}_{4}$ yield.

The relations between each volatile metabolite and $\mathrm{CH}_{4}$ intensity including FPCM as a covariate are shown in Table 1. Including FPCM as a covariate in the regression model resulted in no relationship between the volatile metabolites and $\mathrm{CH}_{4}$ intensity (Table 1). This suggests that the previous relations were due to a relation between the volatile metabolites and FPCM.

Nonvolatile Metabolites. In the present study, 30 resonances could be assigned either to a compound or to a member of a class of compounds (Supplemental Table S3; http://dx.doi.org/10.3168/jds.2015-10248). The relations between each nonvolatile metabolite and $\mathrm{CH}_{4}$ intensity or $\mathrm{CH}_{4}$ yield are shown in Tables 3 and 4 , respectively. The nonvolatile metabolites, acetoacetate, creatinine, ethanol, formate, methylmalonate, and $N$-acetylsugar A were positively related $(P<0.030)$ to $\mathrm{CH}_{4}$ intensity. Citrate and uridine diphosphate (UDP)-hexose $\mathrm{B}$ were negatively related $(P<0.026)$ to $\mathrm{CH}_{4}$ intensity. None of the nonvolatile metabolites were positively related to $\mathrm{CH}_{4}$ yield, whereas acetone was the only nonvolatile metabolite negatively related $(P=0.046)$ to $\mathrm{CH}_{4}$ yield.

The relations between each nonvolatile metabolite and $\mathrm{CH}_{4}$ intensity, including FPCM as a covariate, are shown in Table 3. When including FPCM as a covariate in the regression model, none of the nonvolatile metabolites were positively related to $\mathrm{CH}_{4}$ intensity (Table 3 ). This suggests that the relation between $\mathrm{CH}_{4}$ intensity and acetoacetate, creatinine, ethanol, formate, methylmalonate, and $\mathrm{N}$-acetylsugar A were due to the relation between these nonvolatiles metabolites and FPCM. Citrate and UDP-hexose B remained negatively related $(P<0.026)$ to $\mathrm{CH}_{4}$ intensity upon including FPCM as a covariate in the regression model. The significant relationship with $\mathrm{CH}_{4}$ intensity in the presence of FPCM as a covariate suggests that the metabolic pathways in which these metabolites are involved relate to $\mathrm{CH}_{4}$ production in dairy cows, independent of FPCM yield.

Our results suggest that relating milk metabolites to $\mathrm{CH}_{4}$ intensity without including FPCM as a covariate may identify milk metabolites that are also or exclusively related to FPCM rather than $\mathrm{CH}_{4}$ emission. This dependency seems to be true for both volatile and nonvolatile metabolites, and indicates that an increase in milk yield may reduce the concentration of some milk constituents. Bovenhuis et al. (2015) reported similar findings showing the genetic polymorphism in the $D G A T 1$ gene related to a higher milk yield and reduced milk protein content. However, changes in milk yield do not account for all the variation in milk composition. Hristov et al. (2015) reported that without changes in milk yield, milk of cows with a lower $\mathrm{CH}_{4}$ production (g/d) due to feeding of 3-nitrooxypropanol had a higher content of de novo synthesized fatty acids. Due to the relation between rumen VFA and de novo synthesized fatty acids, the results of Hristov et al. (2015) suggest that milk composition also depends on blood-derived compounds and mammary gland metabolic activity (Bauman and Griinari, 2003; Jenkins and McGuire, 2006). Taken together, these 2 processes contribute to changes in milk composition, and in our data set it was difficult to distinguish between a dilution effect due to higher milk yield or a higher metabolic activity related to higher milk yield. Therefore, throughout the discussion we will consider them both.

Comparison of Both Techniques. Milk metabolites can be present in solution and be measured by ${ }^{1} \mathrm{H}-\mathrm{NMR}$. Upon heating, some milk metabolites can 
Table 1. Linear regression between methane intensity $\left(\mathrm{g} / \mathrm{kg}\right.$ of fat- and protein-corrected milk; $\left.\mathrm{FPCM}^{1}\right)$ and milk volatile metabolites (peak area ${ }^{2}$ ) and between methane intensity ( $\mathrm{g} / \mathrm{kg}$ of FPCM) and milk volatile metabolites, including FPCM as a covariate

\begin{tabular}{|c|c|c|c|c|c|c|c|c|c|c|c|}
\hline \multirow[b]{2}{*}{$\begin{array}{l}\text { Volatile metabolite } \\
\text { (peak area) }\end{array}$} & \multicolumn{4}{|c|}{$\begin{array}{l}\text { Linear regression between methane intensity } \\
\text { and milk volatile metabolites }{ }^{4}\end{array}$} & \multicolumn{7}{|c|}{$\begin{array}{l}\text { Linear regression between methane intensity and milk volatile } \\
\text { metabolites, including FPCM as a covariate }\end{array}$} \\
\hline & Slope & $\mathrm{SE}$ & Slope $P$ & $\mathrm{R}^{2}$ & $\begin{array}{c}\text { Slope } \\
\text { (volatile) }\end{array}$ & $\mathrm{SE}$ & $\begin{array}{c}\text { Slope } P \\
\text { (volatile) }\end{array}$ & $\begin{array}{l}\text { Slope } \\
\text { (FPCM) }\end{array}$ & $\mathrm{SE}$ & $\begin{array}{l}\text { Slope } P \\
\text { (FPCM) }\end{array}$ & $\mathrm{R}^{2}$ \\
\hline 1-Heptanol & $-2.47 \times 10^{-7}$ & $1.000 \times 10^{-6}$ & 0.855 & 0.001 & $1.79 \times 10^{-7}$ & $1.07 \times 10^{-6}$ & 0.868 & -0.366 & 0.089 & $<0.001$ & 0.388 \\
\hline 1-Heptanol-decanol & $3.35 \times 10^{-6}$ & $2.000 \times 10^{-6}$ & 0.044 & 0.137 & $1.22 \times 10^{-6}$ & $1.48 \times 10^{-6}$ & 0.417 & -0.334 & 0.096 & -0.002 & 0.403 \\
\hline 1-Pentanol & $4.42 \times 10^{-7}$ & $3.755 \times 10^{-7}$ & 0.249 & 0.047 & $2.16 \times 10^{-7}$ & $3.09 \times 10^{-7}$ & 0.490 & -0.355 & 0.089 & $<0.001$ & 0.398 \\
\hline 2-Butanone & $4.49 \times 10^{-8}$ & $5.527 \times 10^{-8}$ & 0.424 & 0.023 & $3.02 \times 10^{-8}$ & $4.43 \times 10^{-8}$ & 0.501 & -0.362 & 0.088 & $<0.001$ & 0.398 \\
\hline 2-Heptanone & $1.60 \times 10^{-7}$ & $1.271 \times 10^{-7}$ & 0.218 & 0.054 & $2.51 \times 10^{-8}$ & $1.04 \times 10^{-7}$ & 0.384 & -0.354 & 0.089 & $<0.001$ & 0.405 \\
\hline 3-Nonanone & $2.47 \times 10^{-6}$ & $6.561 \times 10^{-7}$ & 0.001 & 0.336 & $1.28 \times 10^{-6}$ & $8.16 \times 10^{-7}$ & 0.129 & -0.250 & 0.113 & 0.035 & 0.439 \\
\hline Acetone & $4.55 \times 10^{-10}$ & $3.928 \times 10^{-9}$ & 0.909 & 0.001 & $2.03 \times 10^{-9}$ & $3.16 \times 10^{-6}$ & 0.527 & -0.377 & 0.090 & $<0.001$ & 0.397 \\
\hline Alkane A & $9.76 \times 10^{-7}$ & $1.000 \times 10^{-6}$ & 0.493 & 0.017 & $1.12 \times 10^{-6}$ & $1.10 \times 10^{-6}$ & 0.321 & -0.369 & 0.087 & $<0.001$ & 0.410 \\
\hline Alkane B & $2.11 \times 10^{-6}$ & $2.000 \times 10^{-6}$ & 0.309 & 0.037 & $1.25 \times 10^{-7}$ & $1.73 \times 10^{-6}$ & 0.943 & -0.365 & 0.093 & 0.001 & 0.388 \\
\hline Alkane C & $-1.95 \times 10^{-7}$ & $3.831 \times 10^{-7}$ & 0.614 & 0.009 & $5.38 \times 10^{-8}$ & $3.10 \times 10^{-7}$ & 0.986 & -0.366 & 0.090 & $<0.001$ & 0.388 \\
\hline Benzene-alkane & $2.47 \times 10^{-6}$ & $2.000 \times 10^{-6}$ & 0.184 & 0.062 & $-5.4 \times 10^{-7}$ & $1.68 \times 10^{-6}$ & 0.751 & -0.382 & 0.100 & 0.001 & 0.390 \\
\hline Benzene-compound & $6.16 \times 10^{-7}$ & $6.454 \times 10^{-7}$ & 0.348 & 0.031 & $7.34 \times 10^{-7}$ & $5.04 \times 10^{-7}$ & 0.157 & -0.373 & 0.086 & $<0.001$ & 0.432 \\
\hline Butanoic acid & $6.28 \times 10^{-9}$ & $8.263 \times 10^{-9}$ & 0.454 & 0.020 & $4.94 \times 10^{-9}$ & $6.59 \times 10^{-9}$ & 0.460 & -0.363 & 0.088 & $<0.001$ & 0.400 \\
\hline Cyclohexane & $1.10 \times 10^{-5}$ & $7.000 \times 10^{-6}$ & 0.139 & 0.076 & $-7.53 \times 10^{-7}$ & $6.77 \times 10^{-6}$ & 0.912 & -0.372 & 0.100 & 0.001 & 0.388 \\
\hline Dimethyl-sulfone & $-3.26 \times 10^{-7}$ & $3.190 \times 10^{-7}$ & 0.316 & 0.036 & $-1.69 \times 10^{-7}$ & $2.60 \times 10^{-7}$ & 0.520 & -0.358 & 0.089 & $<0.001$ & 0.397 \\
\hline Ethanol & $5.71 \times 10^{-7}$ & $2.166 \times 10^{-7}$ & 0.013 & 0.199 & $3.20 \times 10^{-7}$ & $1.98 \times 10^{-7}$ & 0.118 & -0.312 & 0.091 & 0.002 & 0.442 \\
\hline Ethyl ester-acetic acid & $1.95 \times 10^{-7}$ & $2.269 \times 10^{-7}$ & 0.398 & 0.026 & $6.75 \times 10^{-8}$ & $1.86 \times 10^{-6}$ & 0.719 & -0.361 & 0.090 & $<0.001$ & 0.391 \\
\hline Hexanal & $-2.13 \times 10^{-9}$ & $2.763 \times 10^{-8}$ & 0.939 & $<0.001$ & $1.21 \times 10^{-8}$ & $2.22 \times 10^{-8}$ & 0.589 & -0.374 & 0.089 & $<0.001$ & 0.394 \\
\hline Hexanoic acid & $6.96 \times 10^{-9}$ & $5.109 \times 10^{-9}$ & 0.184 & 0.062 & $5.34 \times 10^{-9}$ & $4.10 \times 10^{-9}$ & 0.204 & -0.356 & 0.086 & $<0.001$ & 0.424 \\
\hline Hydrogen-azide & $5.22 \times 10^{-8}$ & $2.18 \times 10^{-8}$ & 0.170 & 0.170 & $2.51 \times 10^{-8}$ & $2.01 \times 10^{-8}$ & 0.222 & -0.321 & 0.094 & 0.002 & 0.421 \\
\hline Ketone A & $1.36 \times 10^{-6}$ & $8.571 \times 10^{-7}$ & 0.124 & 0.082 & $9.42 \times 10^{-7}$ & $6.98 \times 10^{-7}$ & 0.187 & -0.349 & 0.087 & $<0.001$ & 0.427 \\
\hline Limonene & $-6.09 \times 10^{-7}$ & $1.400 \times 10^{-5}$ & 0.966 & $<0.001$ & $8.60 \times 10^{-6}$ & $1.13 \times 10^{-5}$ & 0.454 & -0.380 & 0.089 & $<0.001$ & 0.400 \\
\hline Octanoic acid & $1.09 \times 10^{-8}$ & $6.681 \times 10^{-9}$ & 0.113 & 0.087 & $7.84 \times 10^{-9}$ & $5.42 \times 10^{-9}$ & 0.160 & -0.349 & 0.086 & $<0.001$ & 0.431 \\
\hline Tetrahydrofuran & $3.22 \times 10^{-8}$ & $1.283 \times 10^{-8}$ & 0.018 & 0.184 & $9.14 \times 10^{-9}$ & $1.35 \times 10^{-8}$ & 0.503 & -0.327 & 0.106 & 0.005 & 0.398 \\
\hline
\end{tabular}

产 ${ }^{1}$ Fat- and protein-corrected milk $(\mathrm{kg} / \mathrm{d})=[0.337+0.116 \times$ fat $(\mathrm{g} / 100 \mathrm{~g}$ of milk $)+0.06 \times$ protein $(\mathrm{g} / 100 \mathrm{~g}$ of milk $)] \times$ milk yield $(\mathrm{kg} / \mathrm{d})$.

을 $\quad{ }^{2}$ Numbers are peak area values (arbitrary units).

${ }^{3}$ Milk volatile metabolites are ordered alphabetically, $\mathrm{n}=30$

紊 $\quad{ }^{4}$ Parameters were extracted from the equation: $\mathrm{CH}_{4}$ intensity $=\mathrm{a}+\mathrm{b} \times$ volatile metabolite $+\mathrm{e}$, where $\mathrm{a}$ is the intercept of the regression line, $\mathrm{b}$ is the slope of the regression line (N) associated with the volatile metabolite, and e is the error.

Parameters were extracted from the equation: $\mathrm{CH}_{4}$ intensity $=\mathrm{a}+\mathrm{b} \times$ volatile metabolite $+\mathrm{c} \times \mathrm{FPCM}+\mathrm{e}$, where $\mathrm{a}$ is the intercept of the regression line, $\mathrm{b}$ is the slope of the 
be volatized and measured by GC-MS. Ethanol and acetone were the only compounds detected both by ${ }^{1} \mathrm{H}-$ NMR and GC-MS. A positive correlation was found between the (relative) areas of ethanol $\left(P=0.031, \mathrm{R}^{2}\right.$ $=0.401 ; \mathrm{n}=29)$ and acetone $\left(P<0.001, \mathrm{R}^{2}=0.684\right.$; $\mathrm{n}=29)$ measured by both methods. This is an important prerequisite for the combined analysis of milk metabolome.

In our data set, both volatile and nonvolatile metabolites are generally better correlated with $\mathrm{CH}_{4}$ intensity than with $\mathrm{CH}_{4}$ yield. Further, nonvolatile metabolites are also better related to $\mathrm{CH}_{4}$ intensity than volatile metabolites, and the relationship of 2 nonvolatile metabolites (UDP-hexose B and citrate) remained significant after including FPCM as a covariate in the regression model. The weaker relation between volatile metabolites and $\mathrm{CH}_{4}$ intensity might be due to the direct transfer of volatile compounds from diet to milk or the interaction between volatile metabolites and rumen metabolism (Urbach, 1990; Désage et al., 1996; Toso et al., 2002) that are not related to the ruminal pathways leading to $\mathrm{CH}_{4}$ production.

Multivariate Analysis. Principal component analysis was conducted to identify general differences in volatile and nonvolatile metabolite profiles. The extraction of 2 components explained only $46.2 \%$ of the variation of volatile metabolites and $45.0 \%$ of the variation of nonvolatile metabolites (Supplemental Figure
S1A and S1B, respectively; http://dx.doi.org/10.3168/ jds.2015-10248). Further, no clear correlation was found between the groups of variables and the factors.

\section{Changes in $\mathrm{CH}_{4}$ Intensity May Be Related to the 1-Carbon Metabolism and Energy Metabolism Pathways}

Formate is positively related to $\mathrm{CH}_{4}$ intensity; however, when FPCM is included in the regression model the relation is no longer significant. This may be explained by the negative correlation between formate and FPCM ( $P=0.024$, data not shown). The relation between formate and $\mathrm{CH}_{4}$ intensity may therefore be explained by the milk synthesis processes, more specifically the 1-C metabolism in postabsorption pathways. One-carbon donors, including formate, are important in eukaryotic 1-C metabolism as they connect parallel mitochondrial and cytosolic pathways. Activated 1-C compounds, such as formate, are produced by the mitochondria, after which an enzymatic cascade in the cytoplasm will allow formate to be further incorporated in 1-C metabolism (Appling, 1991; Christensen and MacKenzie, 2006). The 1-C metabolism is a housekeeping process involving diverse mechanisms such as biosynthesis of lipids and proteins as well as methylation reactions (Christensen and MacKenzie, 2006). These processes are entwined with milk synthesis (Bian et al., 2015) as

Table 2. Linear regression between methane yield $\left(\mathrm{g} / \mathrm{kg}\right.$ of DMI) and milk volatile metabolites (peak area) ${ }^{1}$

\begin{tabular}{|c|c|c|c|c|c|c|}
\hline $\begin{array}{l}\text { Volatile metabolite } \\
\text { (peak area) }\end{array}$ & Intercept & $\mathrm{SE}$ & Slope & $\mathrm{SE}$ & Slope $P$ & $\mathrm{R}^{2}$ \\
\hline 1-Heptanol & 24.8 & 0.59 & $-1.72 \times 10^{-6}$ & $1.000 \times 10^{-6}$ & 0.184 & 0.062 \\
\hline 1-Heptanol-decanol & 23.4 & 1.33 & $9.52 \times 10^{-7}$ & $2.000 \times 10^{-6}$ & 0.569 & 0.012 \\
\hline 1-Pentanol & 23.8 & 0.98 & $1.18 \times 10^{-7}$ & $3.734 \times 10^{-7}$ & 0.755 & 0.004 \\
\hline 2-Butanone & 23.9 & 0.57 & $2.33 \times 10^{-8}$ & $5.418 \times 10^{-8}$ & 0.671 & 0.007 \\
\hline 2-Heptanone & 24.1 & 0.49 & $5.11 \times 10^{-9}$ & $1.270 \times 10^{-7}$ & 0.968 & $<0.001$ \\
\hline 3-Nonanone & 24.3 & 1.43 & $-8.54 \times 10^{-8}$ & $7.828 \times 10^{-7}$ & 0.914 & $<0.001$ \\
\hline Acetone & 25.1 & 0.54 & $-7.53 \times 10^{-9}$ & $3.545 \times 10^{-9}$ & 0.043 & 0.139 \\
\hline Alkane A & 23.9 & 0.93 & $3.54 \times 10^{-7}$ & $1.000 \times 10^{-6}$ & 0.799 & 0.002 \\
\hline Alkane B & 24.4 & 1.32 & $-4.64 \times 10^{-7}$ & $2.000 \times 10^{-6}$ & 0.819 & 0.002 \\
\hline Alkane C & 24.6 & 0.61 & $-3.53 \times 10^{-7}$ & $3.682 \times 10^{-7}$ & 0.346 & 0.032 \\
\hline Benzene-alkane & 24.4 & 1.31 & $-4.02 \times 10^{-7}$ & $2.000 \times 10^{-6}$ & 0.827 & 0.002 \\
\hline Benzene-compound & 23.9 & 0.43 & $5.53 \times 10^{-7}$ & $6.290 \times 10^{-7}$ & 0.387 & 0.027 \\
\hline Butanoic acid & 24.0 & 0.47 & $3.61 \times 10^{-9}$ & $8.088 \times 10^{-9}$ & 0.659 & 0.007 \\
\hline Cyclohexane & 24.7 & 1.16 & $-4.0 \times 10^{-6}$ & $7.000 \times 10^{-6}$ & 0.587 & 0.011 \\
\hline Dimethyl-sulfone & 23.3 & 0.71 & $3.98 \times 10^{-7}$ & $3.067 \times 10^{-7}$ & 0.205 & 0.057 \\
\hline Ethanol & 23.2 & 1.04 & $2.13 \times 10^{-7}$ & $2.318 \times 10^{-7}$ & 0.366 & 0.029 \\
\hline Ethyl ester-acetic acid & 25.3 & 1.12 & $-2.44 \times 10^{-7}$ & $2.187 \times 10^{-7}$ & 0.273 & 0.043 \\
\hline Hexanal & 24.6 & 0.50 & $-3.53 \times 10^{-8}$ & $2.602 \times 10^{-8}$ & 0.186 & 0.062 \\
\hline Hexanoic acid & 23.9 & 0.42 & $4.08 \times 10^{-9}$ & $5.071 \times 10^{-9}$ & 0.428 & 0.023 \\
\hline Hydrogen-azide & 23.4 & 1.18 & $1.41 \times 10^{-8}$ & $2.310 \times 10^{-8}$ & 0.548 & 0.013 \\
\hline Ketone A & 23.9 & 0.48 & $6.62 \times 10^{-7}$ & $8.608 \times 10^{-7}$ & 0.449 & 0.021 \\
\hline Limonene & 23.5 & 1.23 & $6.85 \times 10^{-6}$ & $1.400 \times 10^{-5}$ & 0.620 & 0.009 \\
\hline Octanoic acid & 23.9 & 0.43 & $5.25 \times 10^{-9}$ & $6.727 \times 10^{-9}$ & 0.442 & 0.021 \\
\hline Tetrahydrofuran & 23.8 & 0.70 & $6.98 \times 10^{-9}$ & $1.374 \times 10^{-8}$ & 0.615 & 0.009 \\
\hline
\end{tabular}

\footnotetext{
${ }^{1}$ Numbers are peak area values (arbitrary units). Milk volatile metabolites are ordered alphabetically, $\mathrm{n}=30$.

${ }^{2}$ Parameters were extracted from the equation: $\mathrm{CH}_{4}$ yield $=\mathrm{a}+\mathrm{b} \times$ volatile metabolite $+\mathrm{e}$, where a is the intercept of the regression line, $\mathrm{b}$ is the slope of the regression line associated with the metabolite, and $\mathrm{e}$ is the error.
} 
Table 3. Linear regression between methane intensity $\left(\mathrm{g} / \mathrm{kg}\right.$ of fat- and protein-corrected milk; $\left.\mathrm{FPCM}^{1}\right)$ and milk nonvolatile metabolites $\left(\right.$ relative area $\left.{ }^{2}\right)$ and between methane intensity ( $\mathrm{g} / \mathrm{kg}$ of FPCM) and milk nonvolatile metabolites, including FPCM as a covariate ${ }^{1}$

\begin{tabular}{|c|c|c|c|c|c|c|c|c|c|c|c|}
\hline \multirow[b]{2}{*}{$\begin{array}{l}\text { Nonvolatile metabolite } \\
\text { (relative peak area) }\end{array}$} & \multicolumn{4}{|c|}{$\begin{array}{l}\text { Linear regression between methane intensity } \\
\text { and milk nonvolatile metabolites } \\
3\end{array}$} & \multicolumn{7}{|c|}{$\begin{array}{l}\text { Linear regression between methane intensity and milk nonvolatile } \\
\text { metabolites, including FPCM as a covariate }\end{array}$} \\
\hline & Slope & $\mathrm{SE}$ & Slope $P$ & $\mathrm{R}^{2}$ & $\begin{array}{c}\text { Slope } \\
\text { (nonvolatile) }\end{array}$ & SE & $\begin{array}{c}\text { Slope } P \\
\text { (nonvolatile) }\end{array}$ & $\begin{array}{c}\text { Slope } \\
\text { (FPCM) }\end{array}$ & SE & $\begin{array}{l}\text { Slope } P \\
\text { (FPCM) }\end{array}$ & $\mathrm{R}^{2}$ \\
\hline Acetate & 36.09 & 40.550 & 0.381 & 0.028 & 12.34 & 28.51 & 0.666 & -0.438 & 0.079 & $<0.001$ & 0.547 \\
\hline Acetoacetate & 193.99 & 72.200 & 0.012 & 0.205 & 75.30 & 59.55 & 0.217 & -0.399 & 0.083 & $<0.001$ & 0.569 \\
\hline Acetone & -33.41 & 23.999 & 0.175 & 0.065 & -17.41 & 17.00 & 0.315 & -0.429 & 0.078 & $<0.001$ & 0.561 \\
\hline Acetylcarnitine & -6.00 & 26.234 & 0.847 & 0.001 & -6.77 & 18.01 & 0.710 & -0.443 & 0.078 & $<0.001$ & 0.546 \\
\hline Betaine & -1.33 & 6.295 & 0.834 & 0.002 & -2.90 & 4.31 & 0.506 & -0.446 & 0.078 & $<0.001$ & 0.551 \\
\hline Butyrate & 3.59 & 2.049 & 0.091 & 0.099 & 1.27 & 1.53 & 0.416 & -0.424 & 0.081 & $<0.001$ & 0.555 \\
\hline BHB & 42.80 & 35.945 & 0.244 & 0.048 & 14.59 & 25.72 & 0.575 & -0.434 & 0.079 & $<0.001$ & 0.549 \\
\hline Carnitine & -2.84 & 16.426 & 0.864 & 0.001 & -14.38 & 11.14 & 0.208 & -0.460 & 0.077 & $<0.001$ & 0.570 \\
\hline Choline & 2.25 & 1.397 & 0.119 & 0.085 & 0.48 & 1.06 & 0.656 & -0.431 & 0.082 & $<0.001$ & 0.547 \\
\hline Citrate & -2.04 & 0.866 & 0.026 & 0.166 & -1.43 & 0.603 & 0.025 & -0.412 & 0.072 & $<0.001$ & 0.622 \\
\hline Creatine & -3.11 & 6.388 & 0.631 & 0.008 & -2.88 & 2.10 & 0.516 & -0.442 & 0.077 & $<0.001$ & 0.551 \\
\hline Creatinine & 130.24 & 45.098 & 0.007 & 0.229 & 58.60 & 36.98 & 0.125 & -0.390 & 0.082 & $<0.001$ & 0.583 \\
\hline Ethanol & 328.82 & 88.707 & 0.001 & 0.329 & 167.66 & 115.62 & 0.159 & -0.367 & 0.092 & $<0.001$ & 0.577 \\
\hline Formate & 225.08 & 98.756 & 0.030 & 0.156 & 63.71 & 80.17 & 0.434 & -0.415 & 0.085 & $<0.001$ & 0.554 \\
\hline Galactose-1-phosphate & -0.31 & 130.124 & 0.998 & $<0.001$ & 42.23 & 89.45 & 0.641 & -0.446 & 0.078 & $<0.001$ & 0.547 \\
\hline Glycerophosphocholine & 2.10 & 1.371 & 0.137 & 0.077 & 1.242 & 0.965 & 0.209 & -0.427 & 0.077 & $<0.001$ & 0.570 \\
\hline Hippurate & 59.46 & 32.558 & 0.079 & 0.106 & 43.00 & 22.41 & 0.066 & -0.425 & 0.074 & $<0.001$ & 0.598 \\
\hline Lactate & 6.73 & 13.128 & 0.612 & 0.009 & 5.83 & 9.01 & 0.523 & -0.442 & 0.077 & $<0.001$ & 0.551 \\
\hline Lactose & -0.72 & 0.387 & 0.074 & 0.11 & -0.485 & 0.270 & 0.084 & -0.422 & 0.075 & $<0.001$ & 0.592 \\
\hline Malonate & -6.60 & 39.219 & 0.868 & 0.001 & 7.254 & 27.07 & 0.791 & -0.445 & 0.078 & $<0.001$ & 0.545 \\
\hline Methylmalonate & 101.03 & 33.512 & 0.005 & 0.245 & 34.28 & 29.93 & 0.262 & -0.392 & 0.088 & $<0.001$ & 0.565 \\
\hline $\mathrm{N}$-Acetylsugar A & 43.12 & 16.054 & 0.012 & 0.205 & 5.31 & 14.94 & 0.724 & -0.424 & 0.094 & $<0.001$ & 0.546 \\
\hline$N$-Acetylsugar B & 0.95 & 2.868 & 0.743 & 0.004 & -3.75 & 2.00 & 0.072 & -0.498 & 0.079 & $<0.001$ & 0.596 \\
\hline$N$-Acetylsugar C & 1.31 & 3.717 & 0.728 & 0.004 & 4.01 & 2.49 & 0.119 & -0.464 & 0.076 & $<0.001$ & 0.584 \\
\hline$N$-Acetylsugar D & 2.36 & 10.318 & 0.821 & 0.002 & 11.23 & 6.93 & 0.117 & -0.469 & 0.076 & $<0.001$ & 0.584 \\
\hline$N$-Acetylsugar E & 24.76 & 28.472 & 0.392 & 0.026 & 32.81 & 18.87 & 0.093 & -0.452 & 0.074 & $<0.001$ & 0.590 \\
\hline Orotate & 3.89 & 25.592 & 0.880 & 0.001 & -4.55 & 17.65 & 0.799 & -0.455 & 0.078 & $<0.001$ & 0.545 \\
\hline Oxaloacetate & 86.94 & 94.549 & 0.366 & 0.029 & 53.89 & 65.46 & 0.418 & -0.437 & 0.077 & $<0.001$ & 0.555 \\
\hline Oxoglutarate & 29.74 & 32.466 & 0.367 & 0.029 & -9.77 & 23.69 & 0.683 & -0.453 & 0.082 & $<0.001$ & 0.547 \\
\hline Phosphocreatine & 1.67 & 32.153 & 0.959 & $<0.001$ & 28.48 & 21.92 & 0.205 & -0.463 & 0.077 & $<0.001$ & 0.571 \\
\hline Phosphorylcholine & -2.38 & 4.010 & 0.558 & 0.012 & 3.21 & 2.88 & 0.274 & -0.473 & 0.081 & $<0.001$ & 0.564 \\
\hline Proline & -37.24 & 19.839 & 0.071 & 0.112 & 3.24 & 16.53 & 0.846 & -0.451 & 0.089 & $<0.001$ & 0.544 \\
\hline Pyruvate & 4.67 & 28.595 & 0.871 & 0.001 & 17.83 & 19.51 & 0.369 & -0.451 & 0.077 & $<0.001$ & 0.557 \\
\hline Succinate & 55.40 & 37.836 & 0.154 & 0.071 & -20.62 & 27.49 & 0.460 & -0.429 & 0.079 & $<0.001$ & 0.553 \\
\hline Sugar A (derivative phosphate) & 4.69 & 55.663 & 0.933 & $<0.001$ & -5.65 & 38.32 & 0.884 & -0.443 & 0.078 & $<0.001$ & 0.544 \\
\hline Sugar B (derivative phosphate) & -13.96 & 31.110 & 0.657 & 0.007 & 33.85 & 22.05 & 0.136 & -0.487 & 0.080 & $<0.001$ & 0.580 \\
\hline Sugar C (derivative phosphate) & -12.93 & 22.771 & 0.575 & 0.011 & 19.06 & 16.31 & 0.253 & -0.474 & 0.081 & $<0.001$ & 0.566 \\
\hline Uridine diphosphate (UDP)-hexose A & -282.90 & 303.410 & 0.359 & 0.03 & -12.78 & 217.50 & 0.954 & -0.442 & 0.080 & $<0.001$ & 0.544 \\
\hline UDP-hexose B & -347.39 & 88.662 & 0.001 & 0.354 & -185.00 & 78.55 & 0.026 & -0.353 & 0.081 & $<0.001$ & 0.621 \\
\hline UDP-hexose C & 144.61 & 76.051 & 0.068 & 0.114 & 87.48 & 54.05 & 0.116 & -0.419 & 0.076 & $<0.001$ & 0.584 \\
\hline UDP-hexose D & -169.83 & 210.770 & 0.427 & 0.023 & -17.70 & 149.15 & 0.906 & -0.441 & 0.079 & $<0.001$ & 0.544 \\
\hline
\end{tabular}

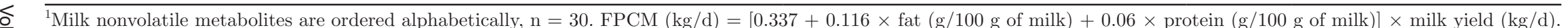

8 Numbers are relative peak area values in relation to the peak area of internal standard (arbitrary units).

z ${ }^{3}$ Parameters were extracted from the equation: $\mathrm{CH}_{4}$ intensity $=\mathrm{a}+\mathrm{b} \times$ nonvolatile metabolite $+\mathrm{e}$, where a is the intercept of the regression line, $\mathrm{b}$ is the slope of the regression line associated with the metabolite, and e is the error.

${ }^{4}$ Parameters were extracted from the equation: $\mathrm{CH}_{4}$ intensity $=\mathrm{a}+\mathrm{b} \times$ metabolite $+\mathrm{c} \times \mathrm{FPCM}+\mathrm{e}$, where $\mathrm{a}$ is the intercept of the regression line, $\mathrm{b}$ is the slope of the regression line associated with the metabolite, $c$ is the slope of the regression line associated with FPCM, and e is the error. 
Table 4. Linear regression between methane yield ( $\mathrm{g} / \mathrm{kg}$ of DMI) and milk nonvolatile metabolites (relative area) $)^{1,2}$

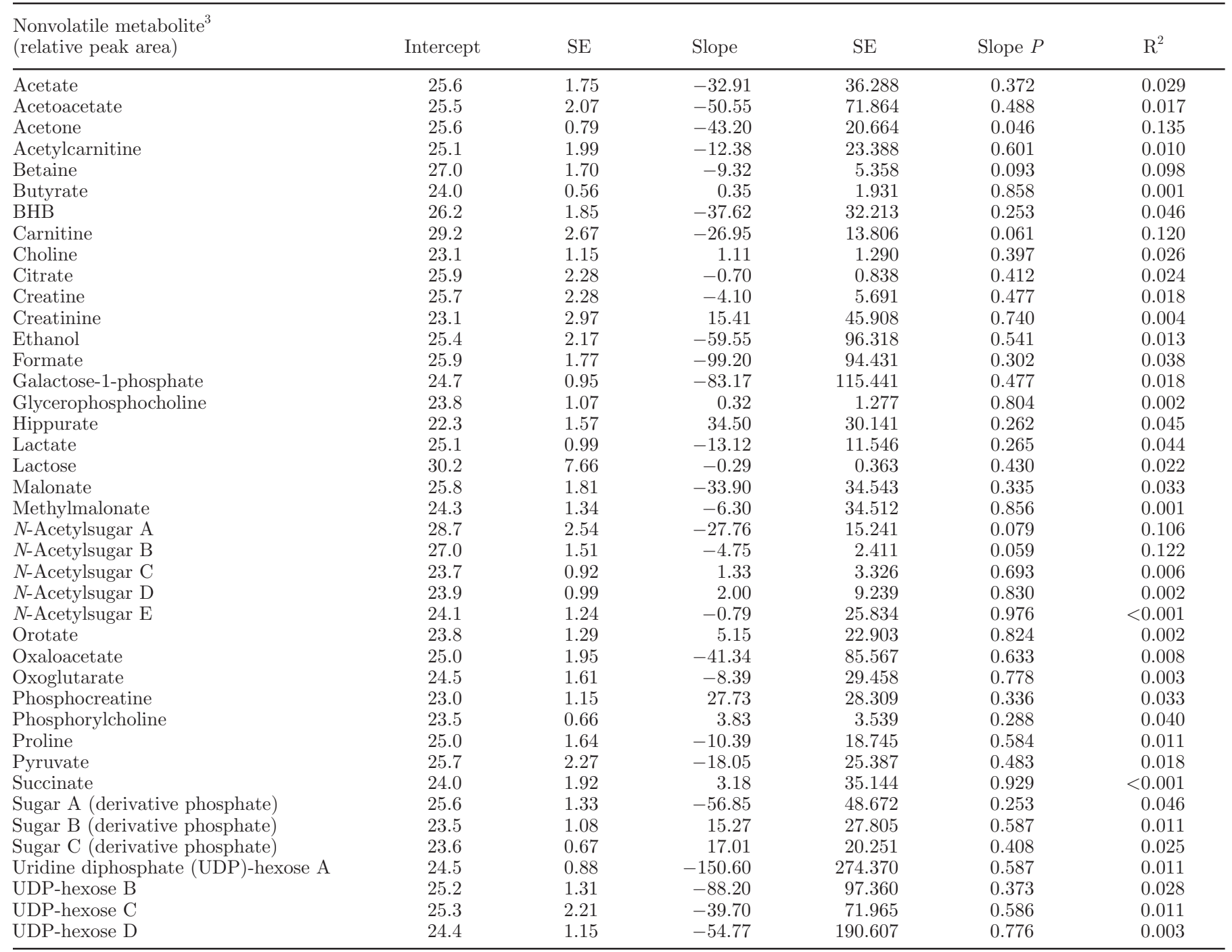

${ }^{1}$ Milk nonvolatile metabolites are ordered alphabetically, $\mathrm{n}=30$.

${ }^{2}$ Numbers are relative peak area values in relation to the peak area of internal standard (arbitrary units).

${ }^{3}$ Parameters were extracted from the equation: $\mathrm{CH}_{4}$ yield $=\mathrm{a}+\mathrm{b} \times$ metabolite $+\mathrm{e}$, where a is the intercept of the regression line, $\mathrm{b}$ is the slope of the regression line associated with the metabolite, and e is the error.

in healthy cows, milk metabolites may be secreted into milk via transcellular routes (McManaman and Neville, 2003). Therefore, a negative relation between formate and FPCM might reflect a change in postabsorption 1-C metabolism, possibly in the mammary gland.

Acetoacetate, together with volatile 3 -nonane, are ketone bodies that are positively correlated with $\mathrm{CH}_{4}$ intensity (Tables 3 and 1, respectively). The presence of ketones bodies in milk is often used to monitor changes in energy metabolism of dairy cows (Enjalbert et al., 2001). A higher amount of ketone bodies in blood plasma and subsequently in milk occurs when there is a surplus of acetyl-CoA for the tricarboxylic acid (TCA) cycle (Enjalbert et al., 2001; Wellen and Thompson, 2012). In general, diets relatively rich in fiber that promote production of the ketogenic VFA, acetic acid, and butyric acid in the rumen may give rise to higher levels of ketone bodies in blood than glucogenic diets (diets relatively rich in rumen bypass starch delivering glucose in the small intestine or rich in rapidly fermentable carbohydrates that promote production of propionic acid in the rumen; van Knegsel et al., 2007). Diet composition is known to be related to $\mathrm{CH}_{4}$ production in the rumen, with fiber generally resulting in higher $\mathrm{CH}_{4}$ production per unit substrate degraded in comparison with starch (Ellis et al., 2008; Hristov et al., 2013). 
Hence, a positive relationship between ketone bodies in milk and $\mathrm{CH}_{4}$ intensity might be explained from the ketogenic or glucogenic nutrient supply to the rumen and its effect on rumen fermentation. However, higher concentrations of these ketone bodies in milk were not significantly related to $\mathrm{CH}_{4}$ yield, indicating that such differences in ketogenic or lipogenic supply to the rumen and effects on rumen fermentation do not have a role in the observed relationships with $\mathrm{CH}_{4}$ intensity. The correlation between acetoacetate, 3-nonanone, and $\mathrm{CH}_{4}$ intensity disappears when FPCM is included as a covariate in the regression model. In fact, acetoacetate and 3-nonanone are negatively related $(P=0.022, P$ $<0.001$, respectively, data not shown) to FPCM. This may indicate a dilution effect of certain milk metabolites due to a higher milk yield.

The TCA cycle in the mitochondria is of paramount significance to the metabolic efficiency of the cell and therefore the metabolism of the cow. In the mitochondria, ATP is produced from acetyl-CoA originating from glucose, fatty acids, lactate, pyruvate, and AA (Hardie and Carling, 1997). The production and utilization of ATP is therefore a flexible situation in which molecules are interconverted depending on the needs of the cell. In this situation, molecules with a high-energy phosphate, such as phosphocreatine, have been widely studied. Together with its precursor creatine, they form an important pool of energy in the cell, which can be used by the mitochondria. A consequence of this metabolism is the formation of creatinine, which is often monitored for energy status of tissues (Wyss and Kaddurah-Daouk, 2000). In our data set, a positive correlation is present between creatinine and $\mathrm{CH}_{4}$ intensity $(P=0.007$, Table 4$)$ and a negative correlation between creatinine and milk yield expressed as FPCM $(P$ $=0.026$, data not shown). Further, the positive correlation between creatinine and $\mathrm{CH}_{4}$ intensity disappears when FPCM is included as a covariate in the regression model. Therefore, in our data set, changes in creatinine concentration in milk seem related to changes in milk yield and therefore milk synthesis. This may indicate a change in the metabolic activity fueled by the mitochondria.

As discussed in this section, a negative relation was found between milk formate, acetoacetate, 3-nonanone, creatinine, and milk yield, expressed as FPCM. This supports the idea of a possible dilution effect on milk metabolites. Further, when FPCM is included as a covariate in the regression models, the above mentioned metabolites are no longer related to $\mathrm{CH}_{4}$ intensity. An increase in $\mathrm{CH}_{4}$ intensity resulting from a lower milk yield may therefore be associated with a lower metabolic rate, explaining the changes in milk metabolites related to milk synthesis and energy metabolism.

\section{Changes in $\mathrm{CH}_{4}$ Intensity Are Related to Lactose Synthesis}

In our data set, $\mathrm{CH}_{4}$ intensity is negatively related to UDP-hexose B $(P=0.001$, Table 3$)$. This negative relation may be due to the fact that UDP-sugars, including UDP-hexoses, are intermediates in lactose synthesis (Cant et al., 2002). For the production of lactose, glucose is transported from the bloodstream into the cytosol of epithelial cells, where part of it is converted into UDP-sugars. These are precursors of galactose that together with glucose will form lactose (Cant et al., 2002). This may explain the positive correlation between UDP-hexose B and lactose yield (g/d; Figure $1 \mathrm{~A})$. Milk yield is mainly controlled by the synthesis of lactose due to the contribution of this disaccharide to the osmolality of milk (Linzell and Peaker, 1971), and as discussed previously, an increase in milk yield (as FPCM) per animal reduces $\mathrm{CH}_{4}$ intensity. Although in our data set UDP-hexose $\mathrm{B}$ is positively related $(P=$ 0.008, data not shown) to FPCM, even when including FPCM in the regression model the UDP-hexose B is still significantly related to $\mathrm{CH}_{4}$ intensity. This suggests that the lower amount of UDP-hexose B in milk might be related to the involvement of glucose in different metabolic pathways in the mammary gland. The large majority of glucose that is taken up by the epithelial cells is used in the biosynthesis of lactose (Cant et al., 2002). Glucose is also involved in NADPH production, which is paramount in the de novo MFA synthesis, and is required to synthesize glycerol, forming the backbone of triglycerides (Dijkstra et al., 1996). Thus, the negative relation between UDP-hexose $\mathrm{B}$ and $\mathrm{CH}_{4}$ intensity may be explained by a decrease in metabolic rate in the mammary gland due to a lower milk yield.

In our data set, milk citrate is negatively related to $\mathrm{CH}_{4}$ intensity $(P=0.026$, Table 3$)$ and is not related to FPCM $(P=0.347$, data not shown). Therefore, when including FPCM in the regression model, citrate is still negatively related to $\mathrm{CH}_{4}$ intensity $(P=0.025$, Table $3)$. Milk citrate is regarded as a marker for the energy metabolism in the mammary gland because the mammary epithelium is impermeable to citrate (Linzell et al., 1976; Faulkner and Peaker, 1982). In our study, a decrease in milk citrate and associated increase in $\mathrm{CH}_{4}$ intensity (Table 3 ) could indicate a disruption in the TCA cycle in the mammary gland because citrate is a regulatory compound of the acetyl-CoA metabolism in the mitochondria (Bremer and Davis, 1974). Further, by providing NADPH, the citrate metabolism and the TCA cycle may be indirectly involved in de novo synthesis of MFA in the mammary gland, inducing a negative correlation between citrate and de novo synthesized MFA (Faulkner and Peaker, 1982). In our 

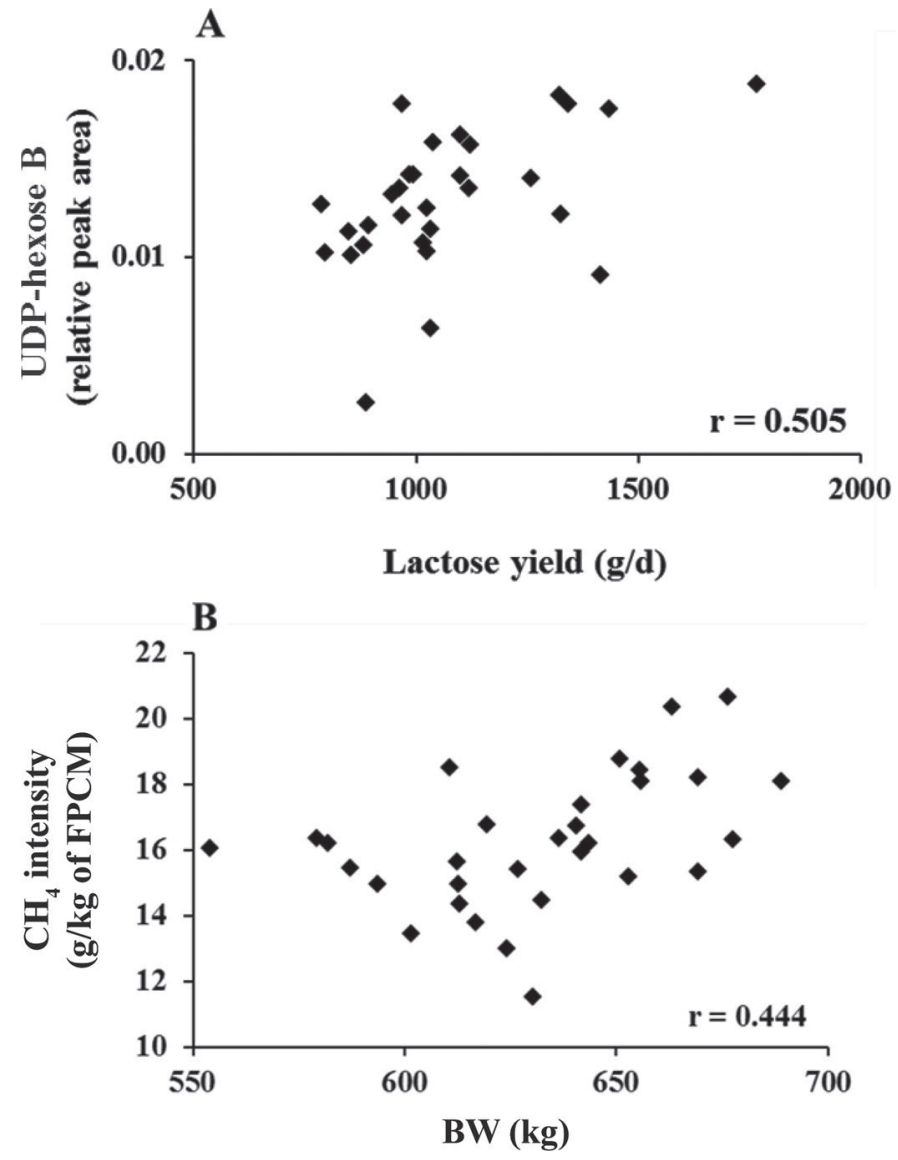

Figure 1. Scatter plots of (A) uridine diphosphate (UDP)-hexose $\mathrm{B}$ and lactose yield $(\mathrm{g} / \mathrm{d})$, and $(\mathrm{B}) \mathrm{CH}_{4}$ intensity $(\mathrm{g} / \mathrm{kg}$ of fat- and protein-corrected milk; FPCM) and BW (kg). r indicates the Pearson correlation coefficient, $\mathrm{n}=30$.

data set, C12:0 and C14:0 were the only de novo synthesized MFA negatively related to milk citrate (data not shown). This may be due to the contribution of NADPH to the elongation step during the de novo MFA synthesis. In each elongation step, rumen-derived acetate and NADPH are needed and longer de novo MFA require more elongation steps and therefore more NADPH; C6:0 requires 2 elongation steps in contrast to the 5 elongation steps needed for C12:0 (Garnsworthy et al., 2006).

Together with NADPH, each elongation step in the de novo synthesis of MFA requires rumen-derived acetate, which mainly originates from fermentation of complex carbohydrates in the rumen. Decreased rates of MFA synthesis in the mammary gland induced by dietary changes have been shown to increase citrate levels of milk (Garnsworthy et al., 2006). Increasing the level of rapidly fermentable carbohydrates by increasing concentrate proportion of the diet, or increasing dietary lipid content, are generally associated with reduced de novo MFA synthesis, and such diets in general are also associated with reduced $\mathrm{CH}_{4}$ production (Ellis et al., 2008). This may further explain the observed negative relationship between citrate and $\mathrm{CH}_{4}$ intensity in the present study.

\section{Milk Acetone Relates to $\mathrm{CH}_{4}$ Yield}

Expressing $\mathrm{CH}_{4}$ emission relative to feed intake avoids confounding effects of DMI on total $\mathrm{CH}_{4}$ production (Dijkstra et al. (2011). In our data set, acetone measured both by ${ }^{1} \mathrm{H}-\mathrm{NMR}$ and GC-MS was the only metabolite negatively related to $\mathrm{CH}_{4}$ yield. Acetone is a ketone body that may be positively or negatively related to milk production. In general, milk acetone levels of energy deficient cows increase rapidly and may indicate subclinical ketosis (Miettinen, 1994), and subclinical ketosis may negatively affect milk production. Milk acetone is also influenced by parity and lactation stage, and a rise in milk production was accompanied by a rise in milk acetone levels (Heuer et al., 2001). In our study, $\mathrm{CH}_{4}$ yield and acetone were not related to milk production (expressed as FPCM; $P<0.675$, data not shown), and therefore the mechanisms explaining the relation between $\mathrm{CH}_{4}$ yield and acetone are not totally clear. In general, levels of ketone bodies including acetone are not just related to energy balance of the cow, but also to glucose levels (Andersson, 1988). As discussed in a previous section, glucogenic diets are generally associated with reduced $\mathrm{CH}_{4}$ production. Therefore, we assessed the effect of diet on the established relations between individual volatile metabolites or nonvolatile metabolites, and $\mathrm{CH}_{4}$ emission, by including dietary treatment as a covariate in the linear regressions. The majority of relations were not significantly changed (data not shown). Only hydrogen-azide became significantly related to $\mathrm{CH}_{4}$ intensity $(P=0.043)$ and sugar A (derivative phosphate) became significantly related to $\mathrm{CH}_{4}$ yield, $(P=0.031)$. More specifically, including treatment as a covariate in the regression model did not significantly change the relation between acetone (nonvolatile) and $\mathrm{CH}_{4}$ yield $(P=0.044)$, but acetone (volatile) was no longer significantly related to $\mathrm{CH}_{4}$ yield $(P=0.229)$. Our results suggest that although acetone may help to understand changes in the physiology of the dairy cow associated with $\mathrm{CH}_{4}$ yield, it may also be influenced by the diet.

\section{Body Weight Relates to $\mathrm{CH}_{4}$ Intensity, But Not to $\mathrm{CH}_{4}$ Yield}

In the present study, BW of cows was positively related to $\mathrm{CH}_{4}$ intensity $(P=0.012, \mathrm{r}=0.444$; Figure 1B), but was not related to $\mathrm{CH}_{4}$ yield $(P=0.671, \mathrm{r}$ $=0.079)$. The importance of $\mathrm{BW}$ in relation to $\mathrm{CH}_{4}$ 
production has been previously acknowledge by other authors who have included $\mathrm{BW}$ in regression equations to predict $\mathrm{CH}_{4}$ production (Kirchgebner et al., 1995; Moraes et al., 2014). In a meta-analysis using a Bayesian model selection procedure, Moraes et al. (2014) identified BW as a key explanatory variable in predicting $\mathrm{CH}_{4}$ emissions, in addition to the key dietary variables energy intake, dietary fiber, and lipid proportions. The association between $\mathrm{BW}$ and $\mathrm{CH}_{4}$ emission might be explained by the relation between $\mathrm{BW}$ and rumen capacity (Demment and Van Soest, 1985). A higher BW is proportional to a larger rumen capacity. When feed intake is kept constant, a higher rumen capacity results in a lower passage rate (Demment and Van Soest, 1985), resulting in a higher $\mathrm{CH}_{4}$ production (Moraes et al., 2014).

Because feed intake, either as DMI or gross energy intake, are confounding factors of $\mathrm{BW}$ and enteric $\mathrm{CH}_{4}$ production (Ellis et al., 2008), cows in the present experiment had a restricted feed intake, and no correlation between $\mathrm{BW}$ and $\mathrm{CH}_{4}$ yield $(P=0.671, \mathrm{r}=$ $0.079)$ or BW and FPCM $(P=0.232, \mathrm{r}=-0.221)$ was observed. A higher BW requires more feed to be used for maintenance purposes, thus having less feed available for milk production, which is expected to increase $\mathrm{CH}_{4}$ intensity. However, the absence of relation between BW and FPCM supports the idea that rumen size and passage rate may explain the positive relation between $\mathrm{BW}$ and $\mathrm{CH}_{4}$ intensity.

\section{CONCLUSIONS}

The results of the present study suggest that milk is a suitable matrix to better understand the biological pathways involved in $\mathrm{CH}_{4}$ emission. In general, milk nonvolatile metabolites have a more pronounced relationship with $\mathrm{CH}_{4}$ emission compared with milk volatile metabolites, especially when referring to $\mathrm{CH}_{4}$ intensity $(\mathrm{g} / \mathrm{kg}$ of $\mathrm{FPCM})$ rather than $\mathrm{CH}_{4}$ yield $(\mathrm{g} /$ $\mathrm{kg}$ of DMI). However, relationships between several metabolites and $\mathrm{CH}_{4}$ intensity are partly dependent on milk production (as FPCM). The relations between milk UDP-hexose B and citrate with $\mathrm{CH}_{4}$ intensity (g/ $\mathrm{kg}$ of FPCM) remained significant when FPCM was included as a covariate in the regression models. The UDP-hexose B is an intermediate metabolite of lactose metabolism, whereas citrate is an important intermediate of Krebs cycle-related energy metabolic processes. This suggests that $\mathrm{CH}_{4}$ intensity may be related to lactose synthesis and energy metabolism in the mammary gland. The negative relation between milk acetone and $\mathrm{CH}_{4}$ yield may be related to glucogenic nutrient supply, and implies that acetone is important to monitor $\mathrm{CH}_{4}$ emission related to feed intake. We observed a positive relationship between $\mathrm{BW}$ and $\mathrm{CH}_{4}$ intensity, which may be related to differences in rumen capacity and rumen passage rate. Our results suggest that an integrative approach including milk production and composition, dietary and animal traits will help to explain the biological metabolism of dairy cows in relation to $\mathrm{CH}_{4}$ emission.

\section{ACKNOWLEDGMENTS}

The research is funded by TI Food and Nutrition (Wageningen, the Netherlands), a public-private partnership on pre-competitive research in food and nutrition.

\section{REFERENCES}

Andersson, L. 1988. Subclinical ketosis in dairy cows. Vet. Clin. North Am. Food Anim. Pract. 4:233-251.

Appling, D. R. 1991. Compartmentation of folate-mediated one-carbon metabolism in eukaryotes. FASEB J. 5:2645-2651.

Bannink, A., M. W. van Schijndel, and J. Dijkstra. 2011. A model of enteric fermentation in dairy cows to estimate methane emission for the Dutch National Inventory Report using the IPCC Tier 3 approach. Anim. Feed Sci. Technol. 166-167:603-618.

Bauman, D. E., and J. M. Griinari. 2003. Nutritional regulation of milk fat synthesis. Annu. Rev. Nutr. 23:203-227.

Bian, Y., Y. Lei, C. Wang, J. Wang, L. Wang, L. Liu, L. Liu, X. Gao, and Q. Li. 2015. Epigenetic regulation of miR-29s affects the lactation activity of dairy cow mammary epithelial cells. J. Cell. Physiol. 230:2152-2163.

Bovenhuis, H., M. H. Visker, H. J. van Valenberg, A. J. Buitenhuis, and J. A. van Arendonk. 2015. Effects of the DGAT1 polymorphism on test-day milk production traits throughout lactation. J. Dairy Sci. 98:6572-6582.

Bremer, J., and E. J. Davis. 1974. Citrate as a regulator of acetylCoA metabolism in liver mitochondria. Biochim. Biophys. Acta 370:564-572.

Cant, J. P., D. R. Trout, F. Qiao, and N. G. Purdie. 2002. Milk synthetic response of the bovine mammary gland to an increase in the local concentration of arterial glucose. J. Dairy Sci. 85:494-503.

Chilliard, Y., C. Martin, J. Rouel, and M. Doreau. 2009. Milk fatty acids in dairy cows fed whole crude linseed, extruded linseed, or linseed oil, and their relationship with methane output. J. Dairy Sci. 92:5199-5211.

Christensen, K. E., and R. E. MacKenzie. 2006. Mitochondrial onecarbon metabolism is adapted to the specific needs of yeast, plants and mammals. BioEssays 28:595-605.

Croissant, A. E., S. P. Washburn, L. L. Dean, and M. A. Drake. 2007. Chemical properties and consumer perception of fluid milk from conventional and pasture-based production systems. J. Dairy Sci. 90:4942-4953.

Demment, M. W., and F. J. Van Soest. 1985. A nutritional explanation for body-size patterns of ruminant and nonruminant herbivores. Am. Nat. 125:641-672.

Désage, M., B. Schaal, J. Soubeyrand, P. Orgeur, and J. L. Brazier. 1996. Gas chromatographic-mass spectrometric method to characterise the transfer of dietary odorous compounds into plasma and milk. J. Chromatogr. B Biomed. Appl. 678:205-210.

Dijkstra, J., J. France, A. G. Assis, H. D. S. C. Neal, O. F. Campos, and L. J. M. Aroeira. 1996. Simulation of digestion in cattle fed sugarcane: prediction of nutrient supply for milk production with locally available supplements. J. Agric. Sci. 127:247-260.

Dijkstra, J., S. M. van Zijderveld, J. A. Apajalahti, A. Bannink, W. J. J. Gerrits, J. R. Newbold, H. B. Perdok, and H. Berends. 2011. Relationships between methane production and milk fatty acid profiles in dairy cattle. Anim. Feed Sci. Technol. 166-167:590-595. 
Ellis, J. L., J. Dijkstra, E. Kebreab, A. Bannink, N. E. Odongo, B. W. McBride, and J. France. 2008. Aspects of rumen microbiology central to mechanistic modelling of methane production in cattle. J. Agric. Sci. 146 (Special Issue 02):213-233.

Enjalbert, F., M. C. Nicot, C. Bayourthe, and R. Moncoulon. 2001. Ketone bodies in milk and blood of dairy cows: Relationship between concentrations and utilization for detection of subclinical ketosis. J. Dairy Sci. 84:583-589.

FAO. 2010. Greenhouse gas emissions from the dairy sector: A life cycle assessment. FAO, Rome, Italy.

Faulkner, A., and M. Peaker. 1982. Reviews of the progress of dairy science: Secretion of citrate into milk. J. Dairy Res. 49:159-169.

Garnsworthy, P. C., L. L. Masson, A. L. Lock, and T. T. Mottram. 2006. Variation of milk citrate with stage of lactation and de novo fatty acid synthesis in dairy cows. J. Dairy Sci. 89:1604-1612.

Gerber, P. J., A. N. Hristov, B. Henderson, H. Makkar, J. Oh, C. Lee, R. Meinen, F. Montes, T. Ott, J. Firkins, A. Rotz, C. Dell, A. T. Adesogan, W. Z. Yang, J. M. Tricarico, E. Kebreab, G. Waghorn, J. Dijkstra, and S. Oosting. 2013. Technical options for the mitigation of direct methane and nitrous oxide emissions from livestock: A review. Animal 7:220-234.

Halmemies-Beauchet-Filleau, A., A. Vanhatalo, V. Toivonen, T. Heikkila, M. R. Lee, and K. J. Shingfield. 2014. Effect of replacing grass silage with red clover silage on nutrient digestion, nitrogen metabolism, and milk fat composition in lactating cows fed diets containing a 60:40 forage-to-concentrate ratio. J. Dairy Sci 97:3761-3776.

Hardie, D. G., and D. Carling. 1997. The AMP-activated protein kinase-fuel gauge of the mammalian cell? Eur. J. Biochem. 246:259 273

Hart, K. J., J. A. Huntington, R. G. Wilkinson, C. G. Bartram, and L. A. Sinclair. 2015. The influence of grass silage-to-maize silage ratio and concentrate composition on methane emissions, performance and milk composition of dairy cows. Animal 9:983-991.

Hettinga, K. A., H. J. F. van Valenberg, T. J. G. M. Lam, and A. C. M. van Hooijdonk. 2008. Detection of mastitis pathogens by analysis of volatile bacterial metabolites. J. Dairy Sci. 91:3834-3839.

Hettinga, K. A., H. J. F. van Valenberg, T. J. G. M. Lam, and A. C. M. van Hooijdonk. 2009. The origin of the volatile metabolites found in mastitis milk. Vet. Microbiol. 137:384-387.

Heuer, C., A. Wangler, Y. H. Schukken, and J. P. Noordhuizen. 2001. Variability of acetone in milk in a large low-production dairy herd: A longitudinal case study. Vet. J. 161:314-321.

Hristov, A. N., J. Oh, J. L. Firkins, J. Dijkstra, E. Kebreab, G. Waghorn, H. P. Makkar, A. T. Adesogan, W. Yang, C. Lee, P. J. Gerber, B. Henderson, and J. M. Tricarico. 2013. Special topicsMitigation of methane and nitrous oxide emissions from animal operations: I. A review of enteric methane mitigation options. J. Anim. Sci. 91:5045-5069.

Hristov, A. N., J. Oh, F. Giallongo, T. W. Frederick, M. T. Harper, H. L. Weeks, A. F. Branco, P. J. Moate, M. H. Deighton, S. R. Williams, M. Kindermann, and S. Duval. 2015. An inhibitor persistently decreased enteric methane emission from dairy cows with no negative effect on milk production. Proc. Natl. Acad. Sci. USA 112:10663-10668

Jenkins, T. C., and M. A. McGuire. 2006. Major advances in nutrition: Impact on milk composition. J. Dairy Sci. 89:1302-1310.

Kirchgebner, M., W. Windisch, and H. L. Müller. 1995. Nutritional factors for the quantification of methane production. Pages 333348 in Ruminant Physiology: Digestion, Metabolism, Growth and Reproduction: Proceedings of the Eighth International Symposium on Ruminant Physiology. W. Von Engelhardt, S. Leonhard-Marek, G. Breves, and D. Giesecke, ed. Ferdinand Enke Verlag, Stuttgart, Germany.

Klein, M. S., M. F. Almstetter, G. Schlamberger, N. Nurnberger, K. Dettmer, P. J. Oefner, H. H. Meyer, S. Wiedemann, and W. Gronwald. 2010. Nuclear magnetic resonance and mass spectrometrybased milk metabolomics in dairy cows during early and late lactation. J. Dairy Sci. 93:1539-1550.

Klein, M. S., N. Buttchereit, S. P. Miemczyk, A. K. Immervoll, C. Louis, S. Wiedemann, W. Junge, G. Thaller, P. J. Oefner, and W.
Gronwald. 2012. NMR metabolomic analysis of dairy cows reveals milk glycerophosphocholine to phosphocholine ratio as prognostic biomarker for risk of ketosis. J. Proteome Res. 11:1373-1381.

Knapp, J. R., G. L. Laur, P. A. Vadas, W. P. Weiss, and J. M. Tricarico. 2014. Invited review: Enteric methane in dairy cattle production: Quantifying the opportunities and impact of reducing emissions. J. Dairy Sci. 97:3231-3261.

Linzell, J. L., T. B. Mepham, and M. Peaker. 1976. The secretion of citrate into milk. J. Physiol. 260:739-750.

Linzell, J. L., and M. Peaker. 1971. Mechanism of milk secretion. Physiol. Rev. 51:564-597.

Lu, J., E. Antunes Fernandes, A. E. Paez Cano, J. Vinitwatanakhun, S. Boeren, T. van Hooijdonk, A. van Knegsel, J. Vervoort, and K. A. Hettinga. 2013. Changes in milk proteome and metabolome associated with dry period length, energy balance, and lactation stage in postparturient dairy cows. J. Proteome Res. 12:3288-3296.

McManaman, J. L., and M. C. Neville. 2003. Mammary physiology and milk secretion. Adv. Drug Deliv. Rev. 55:629-641.

Miettinen, P. V. 1994. Relationship between milk acetone and milk yield in individual cows. Zentralbl. Veterinarmed. A 41:102-109.

Mohammed, R., S. M. McGinn, and K. A. Beauchemin. 2011. Prediction of enteric methane output from milk fatty acid concentrations and rumen fermentation parameters in dairy cows fed sunflower, flax, or canola seeds. J. Dairy Sci. 94:6057-6068.

Moraes, L. E., A. B. Strathe, J. G. Fadel, D. P. Casper, and E. Kebreab. 2014. Prediction of enteric methane emissions from cattle. Glob. Change Biol. 20:2140-2148.

Odongo, N. E., M. M. Or-Rashid, E. Kebreab, J. France, and B. W. McBride. 2007. Effect of supplementing myristic acid in dairy cow rations on ruminal methanogenesis and fatty acid profile in milk. J. Dairy Sci. 90:1851-1858.

R Core Team. 2013. R: A language and environment for statistical computing. R Foundation for Statistical Computing, Vienna, Austria. http://www.R-project.org/.

Settachaimongkon, S., M. J. Nout, E. C. Antunes Fernandes, K. A. Hettinga, J. M. Vervoort, T. C. van Hooijdonk, M. H. Zwietering, E. J. Smid, and H. J. van Valenberg. 2014. Influence of different proteolytic strains of Streptococcus thermophilus in co-culture with Lactobacillus delbrueckii ssp. bulgaricus on the metabolite profile of set-yoghurt. Int. J. Food Microbiol. 177:29-36.

Toso, B., G. Procida, and B. Stefanon. 2002. Determination of volatile compounds in cows' milk using headspace GC-MS. J. Dairy Res. 69:569-577.

Urbach, G. 1990. Effect of feed on flavor in dairy foods. J. Dairy Sci. 73:3639-3650.

van Gastelen, S., E. C. Antunes-Fernandes, K. A. Hettinga, G. Klop, S. J. Alferink, W. H. Hendriks, and J. Dijkstra. 2015. Enteric methane production, rumen volatile fatty acid concentrations, and milk fatty acid composition in lactating Holstein-Friesian cows fed grass silage- or corn silage-based diets. J. Dairy Sci. 98:1915-1927.

van Knegsel, A. T., H. van den Brand, E. A. Graat, J. Dijkstra, R. Jorritsma, E. Decuypere, S. Tamminga, and B. Kemp. 2007. Dietary energy source in dairy cows in early lactation: Metabolites and metabolic hormones. J. Dairy Sci. 90:1477-1485.

van Lingen, H. J., L. A. Crompton, W. H. Hendriks, C. K. Reynolds, and J. Dijkstra. 2014. Meta-analysis of relationships between enteric methane yield and milk fatty acid profile in dairy cattle. J. Dairy Sci. 97:7115-7132.

Vlaeminck, B., and V. Fievez. 2005. Milk odd and branched-chain fatty acids to predict ruminal methanogenesis in dairy cows. Commun. Agric. Appl. Biol. Sci. 70:43-47.

Wellen, K. E., and C. B. Thompson. 2012. A two-way street: Reciprocal regulation of metabolism and signalling. Nat. Rev. Mol. Cell Biol. 13:270-276.

Williams, S. R. O., P. J. Moate, M. H. Deighton, M. C. Hannah, and W. J. Wales. 2014. Methane emissions of dairy cows cannot be predicted by the concentrations of C8:0 and total C18 fatty acids in milk. Anim. Prod. Sci. 54:1757-1761.

Wyss, M., and R. Kaddurah-Daouk. 2000. Creatine and creatinine metabolism. Physiol. Rev. 80:1107-1213. 